\title{
B7 Avaliação de alternativas de meio de cultivo para a produção da eritropoetina humana recombinante expressa em células $\mathrm{CHO}$ em suspensão
}

Alexandre Borges Murad ${ }^{1}$, Esther Vinhais Gutierrez ${ }^{1}$, Tiago Pereira dos Santos ${ }^{1}$, Álvaro Paiva Braga de Sousa ${ }^{1}$, Rodrigo Coelho Ventura Pinto ${ }^{1}$

${ }^{1}$ Bio-Manguinhos, Fiocruz, RJ

Introdução: Com o avanço das técnicas de biologia molecular, os cultivos celulares passaram a ser uma importante plataforma para a produção dos biofármacos, que são proteínas recombinantes com fins terapêuticos, obtidos através de processo biotecnológicos. A manutenção dos cultivos sob condições ideais são de grande importância para a obtenção do produto conforme especificações de qualidade e requisitos de segurança. Desta forma, os meios de cultivo garantem 0 ambiente e o fornecimento de nutrientes às células, possibilitando o funcionamento normal do metabolismo, do crescimento celular e, consequentemente, a correta síntese do produto de interesse. Neste trabalho serão avaliados meios comerciais e mais modernos em alternativa ao utilizado atualmente no processo de obtenção da EPOhr, observando-se a capacidade de promoção de crescimento, produtividade e qualidade da molécula.

Objetivo: Comparar diferentes alternativas de meios de cultivo comerciais livres de soro fetal bovino e componentes animais com o meio de cultivo atualmente utilizado para o cultivo em suspensão de células $\mathrm{CHO}$ secretoras de EPO.

Metodologia: De um banco de células de trabalho, células $\mathrm{CHO}$ secretoras de EPOhr foram cultivadas em frascos estáticos do tipo T25 $\mathrm{cm} 2$ em meio SFM4CHO-Utility ${ }^{\mathrm{TM}}$ (Thermo Hyclone GE), na concentração inicial de 2,0×105 células viáveis $/ \mathrm{mL}$, em seguida em frascos $\mathrm{T} 75 \mathrm{~cm} 2$ de meio SFM4CHO ${ }^{\mathrm{TM}}$ ou HyCell ${ }^{\mathrm{TM}}$ na concentração de $3,0 \times 105$ células viáveis $/ \mathrm{mL}$ e em garrafas rotatórias na concentração de $2,0 \times 105$ células viáveis $/ \mathrm{mL}$ em cinco passagens. A cinética (candidato e controle) foi iniciada a partir da última etapa do sub-cultivo, durando 9 dias. Diariamente, foram retiradas alíquotas para quantificação celular em hemacitômetro corando com Azul de Trypan (Células mortas) e cristal violeta (Células totais) e no equipamento NucleoCounter®.

Resultados: Os meios testados foram introduzidos através de um protocolo de adaptação direta por passagens sucessivas, sendo a substituição realizada na $2^{\text {a }}$ passagem. A adaptação ao meio SFM4CHO ${ }^{\mathrm{TM}}$ apresentou concentração de células viáveis relativamente superior ao controle, com viabilidades acima de $80 \%$. Nesta etapa, o meio HyCell ${ }^{\mathrm{TM}}$ obteve concentração celular inferior ao controle e baixa viabilidade $(<80 \%)$ nas últimas passagens. O meio 
SFM4CHO ${ }^{\mathrm{TM}}$ foi submetido a uma cinética de crescimento, obtendo concentração máxima $2,42 \times 106 \pm 0,06$ células viáveis $/ \mathrm{mL}$ (6이), em comparação com o controle, $1,79 \times 106 \pm 0,05$ células viáveis $/ \mathrm{mL}$ ( $7^{\circ}$ dia). A viabilidade inicial do cultivo no meio testado se manteve na faixa de $80-90 \%$, diferente do controle, que sustentou o cultivo com maior viabilidade, na faixa de $90-100 \%$.

Conclusão: $\mathrm{O}$ meio de cultivo SFM4CHO ${ }^{\mathrm{TM}}$ apresentou boa capacidade de sustentar a proliferação, apesar do protocolo de adaptação direta, e alcançou concentração máxima de células viáveis superior ao controle, indicando possuir melhor desempenho, pois manteve a viabilidade em níveis aceitáveis. Os resultados sugerem que, para o meio HyCell ${ }^{\mathrm{TM}}$, o protocolo de adaptação precisa ser alterado, utilizando-se estratégia de substituição.

Palavras-Chave: Alfaepoetina, Biofármaco, CHO, EPOhr, Roller 